\title{
Environmental tax reform and endogenous growth
}

\author{
A. Lans Bovenberg ${ }^{\mathrm{a}, *}$, Ruud A. de Mooij \\ "Netherlands Bureuu for Economic Policy Analysis (CPB); CentER, Tilburg University; \\ OCFEB; CEPR Tilburg, The Netherlands \\ ${ }^{\natural}$ Nerherlands Bureau for Ecunomic Policy Analysis (CPB); OCFEB, Erasmus University, \\ Rotterdam, The Netherlands
}

Received February 1995; Final version received January 1996

\begin{abstract}
This paper explores how an environmental tax reform impacts pollution, economic growth and welfare in an endogenous growth model with pre-existing tax distortions. We find that a shift in the tax mix away from output taxes towards pollution taxes may raise economic growth through two channels. The first channel is an environmental production externality, which determines the positive effect of lower aggregate pollution on the productivity of capital. The second channel is a shift in the tax burden away from the net return on investment towards profits. The paper also shows that the optimal tax on pollution may exceed its Pigovian level if tax-shifting towards profits is large and production externalities are important.
\end{abstract}

Keywords: Environmental externalities; Economic growth; Double dividend; Second best; Pollution taxes

JEL classification: $\mathrm{H} 23 ; \mathrm{O} 41 ; \mathrm{Q} 28$

\section{Introduction}

The link between environmental policy and economic performance is a controversial issue. Some people argue that society faces a trade-off between economic growth and a better quality of the environment. Others,

- Corresponding author: A.L. Bovenberg, Netherlands Bureau of Economic Policy Analysis (CPB), P.O. Box 80510, 2508 GM The Hague, The Netherlands. Tel. + 3170338 3400; Fax + 3170338 3350; email bovenberg@cpb.nl. 
in contrast, maintain that a more ambitious environmental policy is a necessary condition for sustainable economic growth. In this connection. environmental taxes seem to be a particularly attractive instrument to enhance environmental quality without seriously damaging growth prospects. In particular, by increasing taxes on dirty activities and using the proceeds to cut distortionary taxes on income, governments may be able to reap a 'double dividend,' namely, not only a cleaner environment but also a less distortionary tax system, thereby stimulating economic growth.

This paper extends the literature on environmental tax reform in two directions. First, the analytical literature has thus far explored the double dividend issue only in a static framework (see e.g. Ulph (1992), Bovenberg and De Mooij (1994ab), Bovenberg and Van der Ploeg (1994ab), Oates (1995), Parry (1995) and Schöb (1994)). Numerical analyses have employed an intertemporal framework with exogenous growth (see e.g. Goulder (1995a) and Proost and Van Regemorter (1995)). We, in contrast, employ a dynamic model of endogenous growth, which builds on the endogenous growth mode! of Barro (1990), to analytically explore the link between environmental externalities and distortionary income taxes, which reduce growth below its first-best level.

A second contribution of the paper is to model the environment as a public production factor by incorporating the positive effects of a high quality of the environment on the productivity of private inputs into production. Empirical evidence suggests that pollution causes serious productivity losses both in industrialized countries (see, e.g., Alfsen, Brendemoen and Glomsrød (1992), Brendemoen and Vennemo (1994), and Ballard and Medema (1993)) and in developing countries (see e.g. Van Ewijk and Van Wijnbergen (1995)). Previous analyses of the double-dividend issue have abstracted from externalities affecting production by modelling the environment as a public consumption good. We show that the incorporation of production externalities makes a double dividend more likely.

Our paper is also closely related to the literature on pollution and long-term growth (see e.g. Bovenberg and Smulders (1995), Den Butter and Hofkes (1993), Gradus and Smulders (1993), and Ligthart and Van der Ploeg (1993)). This literature focuses on optimal environmental policies and explores how the social optimum can be sustained in a decentralized economy. Our analysis departs from this first-best world in two major ways. First, we explore the consequences of a reform of the tax system, starting from an initial equilibrium that is not necessarily optimal. Second, in addition to market failures associated with environmental externalities, we allow for tax distortions due to the absence of lump-sum taxation. Hence, the interaction between environmental externalities and distortionary taxes is explored in a second-best world. In this connection, not only do we 
investigate the consequences of an environmental tax reform but we also show how, in the presence of distortionary taxes, the optimal environmental tax deviates from the Pigovian tax.

Whether an environmental tax reform produces a second, non-environmental dividend in addition to the boost of environmental quality depends on how such a reform impacts the growth rate. In particular, by driving a wedge between the marginal social costs and benefits of capital accumulation, distortionary income taxes reduce economic growth below its first-best level. Accordingly, a reform that boosts growth alleviates the deadweight loss from the distortionary income tax. In this way, an environmental tax reform may yield a double dividend, i.e. not only an increase in welfare from environmental amenities but also $n$ increase in welfare from private commodities (so-called private welfare) ${ }^{1}$.

We find that an environmental tax reform harms growth, and hence private welfare, if two conditions are met. First, the positive externality of a better environmental quality on productivity should be small compared to the production elasticity of pollution as a rival input into production. Second, substitution between pollution and other inputs should be rather easy. If these two conditions are met, the government faces a trade-off between, on the one hand, environmental care and, on the other hand, economic growth and private welfare. If substitution between pollution and other inputs is difficult, pollution taxes are less powerful in cutting pollution. At the same time, however, they are a more effective device to tax the quasi-rents from pollution, thereby generating revenues to reduce the distortionary tax on output. Accordingly, an environmental tax reform may raise growth and thus private welfare by enhancing the efficiency of the tax system as a revenue-raising device. A double dividend may emerge also if the production externality is relatively powerful.

In a second-best world with distortionary taxes, the optimal environmental tax generally deviates from the Pigovian tax. We show that the optimal environmental tax lies below the Pigovian ievel if substitution between pollution and capital is relatively easy. However, if substitution is more difficult, the optimal pollution tax may exceed the Pigovian level.

The rest of this paper is organized as follows. Section 2 discusses the model. Section 3 explores the effects of pollution taxes on growth, environmental quality and welfare for the case that the substitution elasticity

\footnotetext{
'Goulder (1995b) provides a survey of the theoretical and empirical double dividend literature. Our definition of the double dividend (i.e. increases in both environmental and private welfare) corresponds to Goulder's concept of the 'strong' version of the double dividend. According to Goulder's terminology, a 'weak' double dividend implies that retuming tax revenues through cuts in distortionary taxes leads to higher weifare compared to recycling these revenues through lower lump-sum taxes.
} 
between capital and pollution equals unity. The case with small substitution possibilities between capital and pollution is investigated in section 4 . Finally, section 5 concludes.

\section{The model}

In endogenous growth models, man-made commodities grow at endogenous growth rates while other inputs are constant. In our model, growth in output is sustainahle because it is consistent with a fixed level of environinental quality. ${ }^{2}$ indeed, after a policy shock, the economy immediately moves towards a so-called balanced growth path on which all man-made goods grow at the same rate while natural variables, including the quality of the environment, remain at a constant level. Transitional dynamics in the ratios between the man-made variables are absent because the model includes only one type of asset, namely capital.

Balanced, sustainable growth should be both feasible and optimal. For growth to be feasible, the production function must meet the so-called 'core' property (see Rebelo (1991)) according to which capital is produced with a constant-returns technology in man-made inputs. Moreover, for the natural inputs to play a non-trivial role in the long run, various substitution elasticities must be unity. The requirement that balanced growth with a constant level of environmental quality not only be feasible but also uptimal imposes restrictions on the utility function (see below). The rest of this section presents the model in more detail. The model equations are contained in table 1. Notation is explained at the end of the table.

Table 1

The model in levels

Firms

Production function

$$
\begin{aligned}
& Y=f[m(K, S), n(A, P)] E^{\eta} \\
& \text { where } n(A, P)=A P^{*}
\end{aligned}
$$

Firm Value

$$
V=\int_{0}^{\infty} D \mathrm{e}^{-x t} \mathrm{~d} t
$$

\footnotetext{
${ }^{2}$ In most endogenous growth models, the inputs that are not man-made take the form of raw iabor. In our model, however, these inputs are supplied by nature. For another endogenous growth model in which growth of output is sustainable, i.e. corsistent with a constant level of environmental quality, see Gradus and Smulders (1993).
} 
Dividends

$$
D=\left(1-T_{y}\right) Y-\left(1-T_{a}\right) A-T_{p} P-I
$$

Investment

$$
I=\dot{K}
$$

Profits

$$
W=D+I-r K
$$

First-Order Conditions

$$
\begin{aligned}
& \left(1-T_{y}\right) \frac{\partial Y}{\partial A}=\left(1-T_{u}\right) \\
& \left(1-T_{y}\right) \frac{\partial Y}{\partial P}=T_{p} \\
& \left(1-T_{y}\right) \frac{\partial Y}{\partial K}=r
\end{aligned}
$$

\section{Households}

Utility

$$
U=\int_{0}^{x} \frac{\left[C E^{\phi}\right]^{1-\frac{1}{\sigma}}}{1-\frac{1}{\sigma}} \mathrm{e}^{-\theta t} \mathrm{~d} t
$$

Household Budget Constraint

$$
K=r K \div W-C
$$

First-Order Condition

$$
\frac{\dot{C}}{C}=\sigma(r-\theta)
$$

\section{Government}

Government Budget Constraint

$$
T_{y} Y+T_{p} P=T_{a} A+S
$$

Environmental Quality

$$
E=e(P)
$$

Walras Law

Goods-market equilibrium

$$
I=Y-S-A-C
$$

\section{Exogenous: $\quad T_{a}, T_{p}, S, K_{0}$}

Endogenous: $\quad Y, P, A, V, D, I, W, C, T, E, r, \pi$

\section{Growth rate}

$$
\pi=\frac{\dot{Y}}{Y}=\frac{\dot{Y}}{K}=\frac{\dot{S}}{S}=\frac{\dot{A}}{A}=\frac{\dot{C}}{C}=\frac{\dot{I}}{l}=\frac{\dot{T_{p}}}{T_{p}}=\frac{\dot{V}}{V}=\frac{\dot{D}}{\dot{D}}=\frac{\dot{W}}{W}
$$




\author{
Notation \\ $Y=$ output \\ $S=$ public investment \\ $P=$ pollution \\ $V=$ value of the firm \\ $C=$ private consumption \\ $E=$ quality of the environment \\ $T_{a}=$ abatement subsidy \\ $\boldsymbol{r}=$ interest rate
}

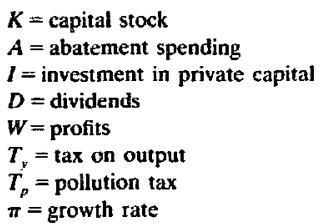

$K=$ capital stock

$I=$ investment in private capital

$D=$ dividends

$W=$ profits

$T_{v}=\operatorname{tax}$ on output

$\pi=$ growth rate

\section{Parameters}

$\boldsymbol{\eta}=$ environmental externality parameter in production

$\phi=$ environmental externality parameter in utility

$\sigma=$ intertemporal substitution elasticity

$\theta=$ pure rate of time preference

$\sigma_{n}=$ substitution elasticity between private capital and public investment

$\sigma_{y}=$ substitution elasticity between intermediates $N=n(A, P)$ and $M=m(K, S)$

\section{Production function}

We extend the production technology in Barro (1990) and Barro and Sala-i-Martin (1992) by including pollution, abatement, and environmental quality as inputs into production. In particular, by using production technology (I.1), firms combine threr private inputs with two public inputs to produce output $(Y)$ (see figure 1). On the one hand, following Barro (1990) and Barro and Sala-i-Martin (1992), physical capital $(K)$ and productive government spending $(S)$, which can be thought of as infrastructure, are combined to produce an intermediate input, $M$. The function $m(K, S)$ exhibits constant returns to scale with respect to the two inputs. On the other hand, by combining pollution $(P)^{3}$ and private abatement $(A)$, firms produce another intermediate input, $N^{4}$ The function $n(A, P)$ features constant returns with respect to the man-made input of abatement, which, in contrast to the natural input of pollution, is growing on a balanced-growth path. Together with the public services from the environment $(E)^{5}$, the two

\footnotetext{
${ }^{3}$ Alternatively, pollution can be modelled as an output (see, e.g., Van der Ploeg and Withagen (1991), Gradus and Smulders (1993) and Smulders and Gradus (1995)). Siebert, Eichenberger, Gronych and Pethig (1980) show that these two modelling approaches are equivalent. In our model, pollution can be interpreted as a polluting input with zero extraction costs. Emissions are proportional to this input.

${ }^{4}$ Abatement is assumed to be a private input, which enables firms to increase output without causing more pollution. Other studies rake abatement as a public, rather than a private, input (see e.g. Nielsen, Pedersen and Sørensen, 1995). In that case, abatement can be viewed as knowledge about 'clean' production methods.

${ }^{5}$ Pollution, $P$, can be viewed as the extractive, rival use of the environment. At the same time, the environment, $E$, yields non-extractive, non-rival services as an input into production.
} 
intermediate inputs, $N$ and $M$, yield output $(Y)$, where the production function $f(M, N)$ exhibits constant returns with respect to $M$ and $N$.

For balanced-growth to be feasible, the production function must meet a number of restrictions. ${ }^{5}$ First, the production function must meet the core property by exhibiting constant returns with respect to the growing inputs:

$$
\delta+\beta+\gamma=1
$$

where $\delta, \beta$ and $\gamma$ denote the production elasticities of the growing inputs $S$, $K$ and $A$, respectively.

The second condition for balanced-growth is that the production elasticities of the various inputs at the left-hand side (LHS) of (2.1), as well as the production elasticity of pollution $(\alpha y)$, remain constant over time. This imposes restrictions on the substitution possibilities between the various inputs. In particular, on a sustainable growth path, the fiow of pollution $(P)$ is constant, while abatement $(A)$ grows at the same rate as output. In the face of these diverging growth rates, the production elasticities of pollution and atatement (i.e. $\alpha \gamma$ and $\gamma$ ) remain constant only if the elasticity of substitution between the non-growing input, $P$, and tise growing input, $A$, equals unity. In particular, if substitution would be too easy (i.e. the substitution elasticity $>1$ ), the production elasticity of pollution would approach zero as the growing input (abatement) would crowd out the non-growing input (pollution). If substitution would be too difficult (i.e. the substitution elasticity $<1$ ), in contrast, the production elasticity of abatement would go to zero because the marginal product of abatement would fall substantially as the abatement-pollution ratio rises. For the same reasons, the elasticity of substitution between $f(N, M)$, which grows on the balanced-growth path, and the quality of the environment, which remains constant, should equal unity. Finally, the substitution elasticity between $K$ and $S$, denoted by $\sigma_{m}$, as well as the substitution elasticity between $M$ and $N$, denoted by $\sigma_{y}$, should be constant. However, these elasticities are allowed to differ from unity as the arguments in $m$ and $f$ (i.e. $K, S$ and $M$, $N$, respectively) grow at the same constant rate.

\section{Firm behavior}

The model describes a decentralized economy with perfect competition. A

Smulders and Gradus (1995, sections 3 and 4) and Bovenberg and Smulders (1995. section 3) formally derive the necessary conditions for balanced growth.

${ }^{7}$ If abatement would not enter the model, the substitution slasticity between (constant) pollution and the (gruwing) intermediate inpet, $M$, would be restricted to unity (see the analysis in section 3). Incorporating abatement thus enables us to examine alternative substitution possibilities. Section 4 indicates that this is potentialy important. 


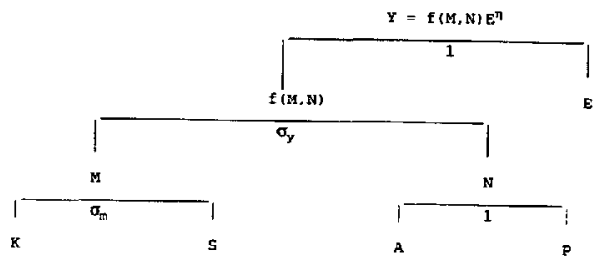

Fig. 1. Production structure.

representative firm maximizes its value (I.2) with respect to abatement, pollution and investment. It ignores the environmental production externality. The value of the firm amounts to the present value of all future dividends, represented by (I.3). $T_{y}$ stands for a tax on output, $T_{a}$ represents an abatement subsidy and $T_{p}$ denotes a pollution tax. The interest rate, denoted by $\because$ is constant on a balanced-growth path. We abstract from depreciation of capital. Hence, the accumulation of capital $(\dot{K})$ equals gross investment (I) (see (I.4)).

Profits $(W)$ in (1.5) are defined as dividends plus investment minus capital costs. ${ }^{8}$ Positive profits can exist in equilibrium due to the presence of a fixed factor (e.g., land, know how, managerial talent), which constitutes a barrier for entering firms. Solving the maximization problem of the firm, we find the implicit demand equations for private inputs (I.6), (I.7) and (1.8). These expressions reveal that firms equalize the marginal productivity of private inputs to their respective producer prices.

\section{Household Behavior}

A representative household maximizes an intertemporal utility function (I.9) subject to a dynamic budget constraint (I.10). Two arguments enter instantaneous utility: private consumption $(C)$ and the quality of the environment $(E)$.

\footnotetext{
${ }^{8}$ Non-negative firm profits (i.e. $s_{w}=\left(1-T_{y}\right)(\delta-\alpha \gamma) \geqslant 0$ ) require that the production elasticity of pollution at the firm level $(\alpha \gamma)$ does not exceed the production elasticity of public investment $(\delta)$. With production featuring constant returns with respect to the growing inputs, $S, A$ and $K$ (see (2.1)), the non-negativity condition for profits guarantees that the production function does not exhibit increasing returns with respect to the 'private' inputs $P, A$ and $K$. Merger across firms is thus not beneficial and a competitive equilibrium can be sustained. Hence, perfect competition is possible only if public infrastructure enters the production function.
} 
The substitution elasticity between the growing variable, $C$, and the quality of the environment, $E$, must be unity to ensure that balanced sustainable growth is optimal from a social point of view. Intuitively, on a balanced growth path, optimal saving rates and the optimal demand for environmental services should not respond to output becoming more abundant relative to environmental quality. This requires that the elasticity of marginal utility $U_{c c} \mathrm{C} / U_{c}$ be corstant. Moreover, the positive income effect on the demand for environmental services, which is triggered by output growth, exactly offsets the negative substitution effect on account of a rising shadow price of environmental quality. If the substitution elasticity were smaller than unity, the income effect would dominate the substitution effect so that saving rates, and hence growth, would decline as produced goods become more abundant relative to environmental quality. If the substitution elasticity between $C$ and $E$ would exceed unity, in contrast, saving rates and hence growth rates would increase over time as the substitution effect would dominate the income effect. In that case, produced goods would substitute for environmental amenities in the long run so that these amenities would not be relevant for long-run utility (see Smulders and Gradus (1995) and Bovenberg and Smulders (1995)).

Maximizing household utility subject to the household budget constraint, one finds the Keynes-Ramsey rule (I.11).

\section{Government}

The government budget is balanced according to (I.12). The government does not issue public debt and raises revenues by adopting a positive tax rate on output $\left(T_{y}\right)$, which is constant on a balanced-growth path, and a positive tax rate on pollution $\left(T_{p}\right)$, which grows at the same rate as output so as to keep constant the share of pollution tax revenues in output, i.e. $T_{p}^{*}=T_{p} P /$ $Y$. The revenues from these taxes are used to finance two types of government spending, which grow at the rate of output: public investment $(S)$ and abatement subsidies $\left(T_{a}\right)$. The government balances its budget at each point in time by adjusting the tax rate on output.

\footnotetext{
'For the steady state to be meaningful, the consumption share of output should be non-negative. This condition ensures also that utility is bounded. From (I.S) and (I.10), we know that $s_{c}=s_{d t}$. On a balanced-growth path, $D$ is growing at a constant rate, $\pi$. Solving the integral (1.2), we derive: $s_{c}=s_{d}=(r-\pi) s_{\nu}$. Hence, the growth rate, $\pi$, should not exceed the interest rate. This condition restricts the rate of time preference $(\theta)$ and the intertemporal elasticity of substitution ( $\sigma$ ). In particular, by using (1.11), we find that a nom-negative consumption share requires that: $\theta \sigma+(1-\sigma) r \geqslant 0$. Hence, the intertemporal substitution possibilities cannot be too large, especially if the rate of time freference is small.
} 


\section{Environmental Quality}

Relation (I.13) formalizes the inverse relationship between the quality of the environment and the flow of pollution. ${ }^{10}$ Environmental quality in the initial equilibrium is assumed to be well above a certain ecological thresinold level. Environmental quality remains above this critical load because pollution does not grow on the balanced-growth path while the policy shocks we consider are infinitely small.

\section{Walras Law: equilibrium conditions and budget constraints}

The model describes a closed economy. The equilibrium condition on (1.14) can be found by combining (I.3), (I.4), (I.5), (I.10) and (I.12) for dividends, investment, profits, the household budget constraint and the government budget constraint, respectively.

\section{Lineurized model}

To solve the model, we log-linearize it around a steady state. Appendix A derives the log-linearized factor-demand equations. Table 2 contains the log-linearized model. Notation is explained at the end of the table. A tilde $(\sim)$ denotes a relative change, unless indicated otherwise. Relative changes in the growing variables are presented relative to the relative change in the capital stock and are presented as lower case variables. Hence, these variables represent relative changes of variables as a ratio to the capital stock (which is initially predetermined). For example, the change in the pollution tax, which is a growing variable, is given by $\tilde{t}_{p}=\tilde{T}_{p}-\tilde{K}$.

Expression (II.2) reveals that a higher relative price of pollution induces substitution from pollution towards other inputs. The strength of the substitution effect towards either abatement or capital depends on the magnitude of $\sigma_{v}$. In particular, if $\sigma_{y}<1$ (as in section 4 below), substitution between the intermediate factors $M$ and $N$ is difficult relative to substitution

\footnotetext{
${ }^{111}$ Altematively, the quality of the environment could be modelled as a stock rather than as a flow (sce e.g. Bovenberg and Smulders (1995)). However, this would complicate the nodel substantially as it would imply a second state variable, thereby introducing transitional dynarnics. More importantly, the qualitative steady-state results do not change if a stock, rather than a flow, determines the external effects (see Smulders and Gradus (1995), appendix A). Hence, if one is interested in long-term effects, the assumption of a flow of pollution involves no loss of generality. In more complicated models with stock-flow dynamics, issues of stability and existence of a steady state may arise (see Tahyonen and Kuuluvainen (1993)). However, stability and existence can be established in simple models that include environmenial quality as a stock (see Bovenberg and Smulders (1994)).
} 
between $A$ and $P$. In that case, pollution and abatement are substitutes: a higher price for abatement increases pollution. However, if $\sigma_{y}>1$, compared to other inputs, pollution is a poor substitute for abatement. Therefore, a higher relative price for abatement lowers pollution. Pollution can be affected also by public investment. In particular, lower public investment raises pollution if $\sigma_{m}<\sigma_{\mu}$. In that case, compared to capital, pollution is a better substitute for public investment. The demand for abatement rises with the level of pollution, abatement subsidies and pollution taxes (see (II.3)).

Relations (II.7) and (II.8) reveal that the economy grows faster if and only if the interest rate increases. This is because a higher interest rate is associated with a higher after-tax return to capital, which stimulates savings and investment." According to (II.9), consumption rises if profits increase. Consumption is affected also by the income and intertemporal substitution effects associated with changes in the interest rate. In particular, if the intertemporal elasticity of substitution $(\sigma)$ exceeds unity, the intertemporal substitution effect dominates and consumption declines on account of a higher interest rate.

Table 2

The model in relative changes

Output

$$
\tilde{y}=\delta \tilde{s}+\gamma \tilde{a}+\alpha \gamma \tilde{P}+\eta \tilde{E}
$$

Pollution

$$
\left[1+\alpha\left(1-\sigma_{y}\right) \mid \tilde{P}=\frac{\delta\left(\sigma_{m}-\sigma_{y}\right)}{\sigma_{m}(\delta+\beta)} \tilde{s}-\left(1-\sigma_{y}\right)\left(\tilde{t}_{\rho}+\tilde{T}_{u}\right)+\sigma_{y}\left(\tilde{r}-\tilde{t}_{p}\right)\right.
$$

Abatement

$$
\tilde{\boldsymbol{a}}=\tilde{\boldsymbol{P}}+\tilde{\boldsymbol{T}}_{\mathrm{a}}+\tilde{t}_{\rho}
$$

Rate of return to capital

$$
\tilde{y}=\frac{\delta\left(\sigma_{m}-\sigma_{v}\right)}{\sigma_{m}(\delta+\beta)} \tilde{s}+\left(1-\sigma_{r} m \tilde{E}+\sigma_{y}\left[\tilde{F}+\tilde{T}_{v}\right]\right.
$$

Dividends

$$
s_{i 1} \bar{d}=-s_{i} \bar{i}+\left(1-T_{v}\right\}\left[\delta \tilde{s}+\gamma \bar{T}_{s}-\tilde{T}_{y}-\alpha \gamma \bar{t}_{p}-\epsilon \eta \bar{P}\right\}
$$

\footnotetext{
"To ensure that growth is positive in the initial equilibrium, we assume that the interest rate exceeds the pure rate of time preference in the initial equilibrium (see 1.II). Since we consider only marginal changes in the tax system, growth remains positive after the tax reform. Hence, if irreversible investments would restrict the growth -ate to be non-negative, a boundary solution with zero growth could not occur. For an analysis of a model with negative growth, see Smulders and Gradus (1995). With negative growth, utility is declining over time. According to the terminology of Pezzey (1992), this implies that the economy is not sustainable.
} 
Profits

$$
s_{n} \tilde{w}=s_{d} \bar{d}+s_{d} \bar{i}-r s_{k} \tilde{r}
$$

Growth gate

$$
\tilde{\pi}=\bar{i}
$$

Household savings

$$
i=\frac{r}{r-\theta} \tilde{r}
$$

Housebold budget constraint

$$
s_{\varepsilon} \tilde{c}=s_{\psi} \tilde{w}+(\tilde{i}-\sigma) r s_{k} \tilde{r}
$$

Government Budget constraint

$$
\left(1-T_{v}\right) \tilde{T}_{v}+T_{y} \tilde{y}+T_{p}^{*} \tilde{t}_{p}+T_{p}^{*} \vec{P}=\left(1-T_{a}\right) s_{a} \bar{T}_{v}+T_{a} s_{u} \tilde{a}+s_{s} \tilde{x}
$$

Environmental Quality

$$
\tilde{E}=-\epsilon \tilde{P}
$$

Goods-market equilibrium (Walras Law)

$$
s_{i} \vec{i}=\vec{y}-s_{i} \bar{c}-s_{a} \tilde{a}-s_{,} \tilde{s}
$$

Capital letters $(X)$ denote levels of a variable, while lower-case variables $(x)$ denote levels as a ratio of the capital sxcek $(K)$, i.e. $x=X / K$ for $x=y, s, a, t_{p}, d, v, w, i, c$ and $\tilde{x}=\bar{X}-\bar{K}$.

\section{Elasticities}

$$
\beta=\frac{\frac{\partial Y}{\partial K} K}{Y}, \delta=\frac{\frac{\partial Y}{\partial S} S}{Y}, \gamma=\frac{\frac{\partial Y}{\partial A} A}{Y}, a \gamma=\frac{\frac{\partial Y}{\partial P} P}{Y}, \epsilon=-\frac{\partial e}{\partial P} \frac{P}{e}>0
$$

Taxes

$$
\tilde{T}_{u}=\frac{\mathrm{d} T_{a}}{1-T_{a}}, \quad \tilde{T}_{4}=\frac{\mathrm{d} T_{b}}{1-T_{v}}, \quad \tilde{T}_{p}=\frac{\mathrm{d} T_{F}}{T_{p}}
$$

Shares

$$
\begin{array}{llll}
s_{a}=A / Y & s_{d}=D / Y & T_{i}^{*}=T_{p} P / Y & s_{n}=W / Y \\
s_{s}=S / Y & s_{c}=C / Y & s_{d}=I / Y & s_{k}=K / Y \\
s_{v}=V / Y & & &
\end{array}
$$

Relations berween the shares

$$
\begin{array}{ll}
\text { Dividends } & s_{d}=\left(1-T_{y}\right)-\left(1-T_{d}\right) s_{d}-T_{v}^{*}-s_{d} ; s_{d}=(r-\pi) s_{v} \\
\text { Profits } & s_{w}=s_{d}+s_{t}-r s_{k}=\left(1-T_{y}\right)(\delta-\alpha \gamma) \\
\text { Household Budget Constraint } & s_{v}=s_{*}+(r-\pi) s_{k} ; s_{c}=s_{d} \\
\text { Definition of investment } & s_{i}=\pi s_{k}
\end{array}
$$


Government Budget Constraint

Goods-Market Equilibrium

$$
\begin{aligned}
& s_{s}+T_{d} s_{u}=T_{y}+T_{p}^{*} \\
& s_{s}=1-s_{,}-s_{a}-s_{c}
\end{aligned}
$$

Production elasticities

$$
\begin{aligned}
& \left(1-T_{v}\right) y=\left(1-T_{4}\right) s_{u} \\
& \left(1-T_{v}\right) \alpha \gamma=T_{p}^{*} \\
& \left(1-T_{v}\right) \beta=r s_{k}
\end{aligned}
$$

\section{Welfare}

The welfare effects of small policy changes can be measured by the marginal excess burden. It amounts to the additional consumption that needs to be provided to the household to keep utility (after the policy shock) at its initial level. Hence, a negative value for the marginal excess burden corresponds to a rise in welfare. The marginal excess burden $\tilde{\lambda} \equiv \mathrm{d} \lambda / C$ amounts to (see appendix $\mathrm{B}$ ):

$$
\begin{aligned}
\tilde{\lambda}= & -\left[\frac{\alpha \gamma-\epsilon \eta}{s_{c}}-\epsilon \phi\right] \tilde{P}-\frac{T_{y}-T_{a}}{1-T_{a}} \frac{\gamma}{s_{c}}\left[\tilde{a}+\frac{\pi}{r-\pi} \tilde{\pi}\right] \\
& -\frac{\delta-s_{s}}{s_{c}}\left[\tilde{s}+\frac{\pi}{r-\pi} \tilde{\pi}\right]-\frac{T_{y} \beta}{s_{c}} \frac{\pi}{r-\pi} \tilde{\pi}
\end{aligned}
$$

All coefficients at the right-hand side (RHS) of (2.2) represent wedges between the marginal social costs and the marginal social benefits of an activity. If benefits exceed costs at the margin, an increase in such activity enhances welfare. For the growing variables $A, S$ and $K$, expression (2.2) reveals that not only changes in current levels matier for welfare, but also the present value of future changes (indicated by the change in the growth rate).

The first term at the RHS of (2.2) stands for the welfare effect of a change in pollution, which is a non-growing variable. First, as a private input into production, pollution exerts a positive effect on output, which is represented by $\alpha \gamma$. Second, by worsening environmental quality, pollution imposes an adverse production externality, captured by $\epsilon \eta$. The overall effect on productivity is positive only if $\alpha \gamma-\epsilon \eta>0$, i.e. if the positive output effect of additional poilution as a rival input for the individual firm exceeds the negative external (non-rival) productivity effect of aggregate pollution. Finally, pollution yields an adverse consumption externality (see the last term between the first square brackets).

The second term at the RHS of (2.2) reveals that higher current or future abatement improves welfare if the output tax, which acts as an implicit tax 
on abatement, exceeds the abatement sıbsidy. Hence, more abatement boosts welfare only if it is taxed on a net basis. ${ }^{12}$

The partial welfare effect of higher public investment is captured by the third term at the RHS of (2.2). A rise in public investment improves welfare if the productivity effect of public investment exceeds the share of public investment in output. This condition implies that the marginal product of public investment is larger than unity, i.e. $d Y / d S>1$ or, alternatively, that the marginal social benefits, $d Y$, exceed the marginal social costs, $d S$.

The last term at the RHS of (2.2) represents the welfare impact of marginal changes in the rates of capital accumulation. The tax on output drives a wedge between the before-tax return to capital (which stands for the marginal social benefits of capital accumulation) and the after-tax return to capital (which measures the marginal social costs of capital accumulation) so that the growth rate of capital is too low from a social point of view. Accordingly, a higher rate of capital accumulation (i.e. $\tilde{\pi}>0$ ) improves welfare because the benefits in terms of higher future output exceed the costs in terms of current consumption foregone.

The double dividend discussion has focussed on tax distortions rather than spending distortions. Hence, we abstract from distortions associated with inefficient levels of public spending on infrastructure and abatement subsidies by setting $T_{a}=T_{y}$ and $\delta=s_{s}$. Changes in abatement or public investment thus yield no first-order effects on welfare. This allows us to concentrate on the interaction between the environmental distortion (i.e. the first term at the RHS of (2.2)) and the tax wedge distorting growth (i.e. the fourth term at the RHS of (2.2)). In particular, an environmental tax reform yields a double dividend if it not only cuts pollution but also alleviates the tax distortion by boosting growth. ${ }^{13}$

\section{Effects on growth, pollution and welfare}

This section explores the economic, ecological and welfare effects of higher pollution taxes (i.e. $\tilde{t}_{p}>0$ ). Appendix $C$ solves the model from table 2 for the special case that abatement subsidies and the share of public investment spending in the capital stock remain constant (i.e. $\tilde{T}_{a}=\tilde{s}=0$ ). This section discusses the results for a sub-production function $f(N, M)$ of

\footnotetext{
${ }^{12}$ This is the partial effect. Abatement affects welfare also by impacting pollution. This indirect effect is represented by the first te:m at the RHS of (2.2).

${ }^{13}$ If $\delta>s$, and $T_{v}>T_{4}$, growth would boost welfare not only by alleviating the tax distortion but also by reducing distortions due to inefficient levels of expenditure on infrastructure and abatement subsidies. In that case, we could talk about triple or quadruple dividends.
} 
the Cobb-Douglas type (i.e. $\sigma_{y}=1$ ), ${ }^{14}$ while section 4 examines the more general case in which $\sigma_{y}$ is allowed to differ from unity.

\section{Effects on growth and environment}

The reduced-form equations for the growth rate, pollution and the tax rate on output are given by:

$$
\begin{aligned}
& \tilde{\pi}=-\frac{r}{r-\theta} \frac{1}{\Delta}(\alpha \gamma-\epsilon \eta) \tilde{t}_{p} \\
& \tilde{P}=-\tilde{t}_{p}-\frac{1}{\Delta}(\alpha \gamma-\epsilon \eta) \tilde{t}_{p} \\
& \tilde{T}_{y}=\frac{s_{s}}{\Delta}(\alpha \gamma-\epsilon \eta) \tilde{t}_{p}
\end{aligned}
$$

where $\Delta \equiv r s_{k}+s_{w}-(\alpha \gamma-\epsilon \eta)>0 .^{15}$

Expression (3.2) reveals that a pollution tax exerts two effects on pollution. First, pollution decreases proportionally due to input substitution (i.e. the first term at the RHS of (3.2)). Hence, the composition of economic activity becomes cleaner. Second, changes in the growth rate affect pollution (see (3.1) and (3.2)). On account of this growth effect, the level of economic activity changes. The overall effect on pollution is unamiguously negative. ${ }^{16}$

The growth effect of an environmental tax reform depends on how such a reform impacts the after-tax rate of return, which determines the incentives to save according to the Keynes-Ramsey rule (I.11). The after-tax return, in turn, is determined by the before-tax of return (i.e. the marginal productivity of capital) and the income tax rate. The net impact on the before-tax return depends on two offsetting effects. On the one hand, a higher pollution tax rate depresses the marginal productivity of capital by reducing the input of pollution. These costs of the pollution tax depend on the production elasticity of pollution, $\alpha \gamma$, which measures the importance of pollution as a private input into production. On the other hand, the improvement in environmental quality associated with the drop in pollution

\footnotetext{
is The value of $\sigma_{m}$ does not affect the analysis because the ratio $S / K$ is fixed. Hence, the sub-production function $m(K, S)$ does not need to be Cobb Douglas.

${ }^{15}$ The determinant, $\Delta$, can be interpreted as the fraction of national income that fows to households. The first term indicates net income from the privately owned capital stock and firm profits. The second term amounts to the net benefits from a lower level of pollution. The determinant should be positive for the equilbrium to be stable.

${ }^{10}$ In particular, the coefficient for the pollution tax at the RHS of (3.2) can be rewritten as:

$$
-\left[1+\frac{1}{\Delta}(\alpha \gamma-\epsilon \eta)\right]=-\frac{1}{\Delta}[\Delta+(\alpha \gamma-\epsilon \eta)]=-\frac{1}{4}\left|r s_{k}+s_{w}\right|<0 .
$$
}

Hence, pollution unambiguously falls. 
enhances the productivity of inputs in production. These public benefits of a lower level of pollution increase with the environmental externality in production, $\eta_{i}$, and the elasticity that measures the effect of pollution on environmental quality, $\epsilon$.

If $\alpha \gamma-\epsilon \eta=0$, a higher pollution tax leaves the marginal product of capital unaffected as the private costs of less polluting inputs (represented by $\alpha \gamma)$ exactly offset the public benefits of a higher level of public environmental services into production (represented by $\epsilon \eta$ ). In this case, not only the before-tax return but also the after-tax return and hence the growth rate (see (3.1)) remain constant because the tax rate on output, $T_{y}$, is unaffected (see (3.3)). The distortionary tax rate must be kept constant because the higher pollution tax does not yield any additional public revenues: with a unitary substitution elasticity, $\sigma_{y}$, the loss of revenue due to the erosion of the base of the pollution tax exactly matches the increase in reverues from the pollution tax due to the increase in the tax rate. Hence, the slope of the Laffer curve for the pollution tax is zero.

The environmental tax reform harms growth if $\alpha \gamma-\epsilon \eta>0$. In this case, the after-tax return declines because of two reasons: a decrease in the before-tax return and an increase in the tax rate on output. The before-tax return to capital falls because the adverse input effect of lower pollution on the marginal productivity of capital dominates the favorable externality effect. The drop in the return to capital erodes the base of the output tax. Accordingly, with revenues from the pollution tax remaining constant, the government is forced to raise the tax rate on output in order to meet its revenue constraint.

If $\alpha \gamma-\epsilon \eta<0$, higher pollution taxes raise the before-tax return. The broadering of the base of the output tax allows for a reduction in the tax rate on output (see (3.3)), thereby ensuring that the after-tax return and thus growth rise. Hence, if the environmental externality in production is large, an environmental tax reform may boost not only the quality of the environment but also growth. Previous analyses of the double dividend issue (see e.g. Ulph (1992), Eovenberg and De Mooij (1994ab) and Bovenberg and Van der Ploeg (1994ab)) have abstracted from production externalities (i.c. $\epsilon \eta=0$ ). In that case, a higher pollution tax always implies a net burden on the production sector and thus reduces growth as $\alpha \gamma>0$.

\section{Welfare effects}

Armed with the economic and ecological effects, we now turn to the effects on welfare, defined by the marginal excess burden in (2.2). The welfare effects of pollution taxes depend on the effects on only pollution and growth (see (2.2) with $T_{a}=T_{y}$ and $\delta=s_{s}$ ). By substituting the reduced-form equations for growth and pollution, (3.1) and (3.2), into (2.2), we derive the following solution for the marginal excess burden: 


$$
\tilde{\lambda}=-\frac{r s_{k}+s_{w}}{\Delta} \epsilon \phi \tilde{t}_{p}+\left[r s_{k}+s_{w}+\frac{\pi}{r-\pi} \frac{r}{r-\theta} T_{y} \beta\right] \frac{1}{\Delta} \frac{\alpha \gamma-\epsilon \eta}{s_{c}} \tilde{t}_{p}
$$

The first term at the RHS of (3.4) reveals that, by cutting the level of pollution, pollution taxes raise welfart by enhancing environmental amenities. Second, if a lower pollution level raises the after-tax return to capital (i.e. $\alpha \gamma-\epsilon \eta<0$ ), pollution taxes enhance private or non-environmental welfare. This private component is captured by the second term at the RHS of (3.4). This term reveals that a higher after-tax return to capital boosts welfare by raising both (current) household income from capital and profits (first term between square brackets) and the growth rate. The welfare impact of changes in the growth rate depends on the wedge between the marginal social costs and benefits of capital accumulation, implied by the distortionary tax on output.

If higher taxes on pollution raise the after-tax return to capital, they yield a double dividend by enhancing not only environmental amenities but also productivity and growth and thus private welfare. If, however, the production externality $(\epsilon \eta)$ is smaller than the production elasticity $(\alpha \gamma)$, higher pollution taxes reduce the after-tax return to capital. In that case, a trade-off exists between, on the one hand, higher environmental amenities and, on the other hand, lower economic growth and private welfare.

\section{Optimal pollution taxes}

The pollution tax is set at its optimal level if a marginal change in its rate leaves welfare unaffected, i.e. if the marginal excess burden is zero. In a first-best world where the government has access to lump-sum taxes, the optimal pollution tax is at the Pigovian level, which fully internalizes the environmental externalities in prociuction and consumption (see (2.2) with $T_{y}=0, T_{a}=0$ and $\left.\delta=s_{s}\right)$ :

$$
\epsilon \phi-\frac{\alpha \gamma-\epsilon \eta}{s_{c}}=0
$$

However, our model is not first-best. In Farticular, the governmen does not have access to lump-sum taxation to finance its public goods. To investigate whether, in this second-best world, the government still finds it optimal to set the environmental tax at its Pigovian level, we substitute (3.5) into (2.2) and arrive at:

$$
\tilde{\lambda}=-\frac{T_{y} B}{s_{c}} \frac{\pi}{r-\pi} \tilde{\pi}
$$

Hence, if $T_{y}>0$, raising the pollution tax above its Pigovian level harms 
welfare if it reduces the growth rate. Indeed, at the Pigovian tax the production elasticity of pollution exceeds the environmental externality in production if environmental amenities are positive (i.e. $\left(\alpha \gamma-\epsilon \eta / s_{c}\right)=\epsilon \phi>$ 0 , see (3.5)). Hence, a higher pollution tax reduces the growth rate (see (3.1)). Intuitively, by internalizing the consumption externality of pollution, environmental taxes reduce the productivity of capital and, therefore, harm growth. This drop in growth produces a first-order loss in welfare, as capital accumulation features a gap between its marginal social costs and marginal benefits.

These results demonstrate that pollution taxes aimed at internalizing environmental externalities may, as a side effect, exacerbate pre-existing distortions in the economy. Indeed, in a second-best world, the optimal tax on pollution differs from its first-best level. In particular, the optimal pollution tax lies below the Pigovian level. Bovenberg and De Mooij (1994a) reach similar conclusions when exploring the interaction between environmental and labor-market distortions. They argue that the optimal pollution tax lies below its Pigovian level because poliution taxes exacerbate the distortion in the labor-market.

\section{Tax-Shifting}

Section 3 assumed a unitary substitution elasticity $\sigma_{y}$, implying that substitution from pollution towards physical capital is relatively easy. In practice, environmental taxes with the most revenue potential involve energy use. Most empirical evidence suggests that substitution possibilities between energy inputs and capital are rather limited (see e.g. Berndt and Wood (1979), Pindyck (1979), Griffin (1981) and Hesse and Tarkka (1986)). In this section, therefore, we allow the substitution elasticity $\sigma_{y}$ to be smaller than unity. Accordingly, pollution taxes imply less factor substitution and thus are more effective as a revenue-raising device. Moreover, compared to capital, abatement is a better substitute for pollution. This does better justice to the term abatement.

\section{Effects on growth and pollution}

The recuced-form equation for pollution amounts to (see appendix C):

$$
\tilde{P}=-\left[1-\frac{\left(1-\sigma_{y}\right)\left(1-T_{y}\right)(1-\gamma) \alpha}{\Delta^{*}}\right] \tilde{t}_{p}-\frac{\sigma_{y}(\alpha \gamma-\epsilon \eta)}{\Delta^{*}} \tilde{t}_{p}
$$

where $\Delta^{*} \equiv \sigma_{y}\left[r s_{k}+s_{w}-(\alpha \gamma-\epsilon \eta \eta)\right]+\left(1-\sigma_{y}\right)\left(1-T_{y}\right)(1-\gamma)(1+\alpha)>0$.

If $\sigma_{y}$ equals unity, (4.1) is identical to (3.2). If substitution between the intermediate factors $M$ and $N$ becomes more difficult, pollution taxes are 
less effective in curting pollution, as they induce less substitution from pollution towards capital. Nevertheless, relation (4.1) reveals that pollution taxes always reduce pollution, even if $\sigma_{y}$ approaches zero."

The reduced-form for the tax rate on output is given by:

$$
\tilde{T}_{y}=\frac{s_{s}}{\Delta^{*}}(\alpha \gamma-\epsilon \eta) \tilde{t}_{p}-\frac{\left(1-\sigma_{y}\right)\left(1-T_{y}\right)(\alpha-\epsilon \eta) \alpha \gamma}{\Delta^{*}} \tilde{t}_{p}
$$

This relationship reveals that if substitution between pollution and capital becomes more difficult (i.e. $\sigma_{y}$ becomes smaller), pollution taxes are more efficient as a revenue-raising device. Indeed, even if pollution taxes involve a negative effect on gross productivity (i.e. $\alpha \gamma-\epsilon \eta>0$ ), they may nevertheless raise a positive amount of public revenues (which are used to cut the tax rate on output).

The effect on the growth rate is given by:

$$
\frac{1}{\sigma} s_{i} \tilde{\pi}=(\alpha \gamma-\varsigma \eta) \tilde{P}-s_{w} \tilde{w}
$$

This expression reveals that the growth performance is affected by two factors, namely, first, the net costs of environmental policy borne by the production sector (i.e. the first term at the RHS of (4.3)), and, second, the part of the costs borne by profits (i.e. the second term at the RHS of (4.3)). As explained in section 3, a tighter environmental policy generates an adverse inapact on growth if a lower pollution level implies a net burden on the production sector. This is the case if $\alpha \gamma-\epsilon \eta>0$, i.e. if the negative output effect of a reduction in pollution as a private rival input exceeds the positive effects associated with less adverse production externalities. The second term at the RHS of (4.3) indicates the effect of shifting the tax burden away from the after-tax return towards profits. In particular, lower profits produce a higher growth rate. Intuitively, taxing away a larger share of profit income creates room to cut the distortionary tax rate on output (see (4.2)), thereby raising the return on capital accumulation.

The reduced-form equation for profits is given by:

${ }^{17}$ The coefficient at the RHS of (4.1) can be rewritten as:

$$
\begin{gathered}
-\left[1-\frac{\left(1-\sigma_{y}\right)\left(1-T_{y}\right)(1-\gamma) \alpha}{\Delta^{*}}+\frac{\sigma_{p}(\alpha \gamma-\epsilon \eta)}{\Delta^{*}}\right]=-\frac{1}{\Delta^{*}} \\
\quad \times\left[\Delta^{*}-\left(1-\sigma_{y}\right)\left(1-T_{y}\right)(1-\gamma) \alpha+\sigma_{y}(\alpha \gamma-\epsilon \eta)\right] \\
=-\frac{1}{\Delta^{*}}\left[\sigma_{y}\left(r s_{k}+s_{n}\right)+\left(1-\sigma_{y}\right)\left(1-T_{y}\right)(1-\gamma)\right]<0 .
\end{gathered}
$$

Hence, pollution unambiguously drops due to higher pollution taxes, even if $a_{y}=0$. 


$$
s_{w} \tilde{w}=-\frac{s_{w}}{\Delta^{*}}(\alpha \gamma-\epsilon \eta) \tilde{t}_{p}-\frac{\left(1-\sigma_{y}\right)\left(1-T_{y}\right)\left[\alpha \gamma-\varepsilon \eta+r s_{k} \alpha\right]}{\Delta^{*}} a \gamma \tilde{t}_{p}
$$

The first term at the RHS of (4.4) represents the effect of input substitution. It reveals that, through this channel, profits share in the burden of environmental policy on the production sector. In particular, pollution taxes harm profits if the adverse pollution externalities on production are small compared to the input share of pollution as a rival input (i.e. $\alpha \gamma-\epsilon \eta>0$ ). The second term at the RHS of (4.4) shows the effect of shifting the tax burden away from the after-tax return on investment towards profits. If $\sigma_{y}<1$, the tax-shifting effect causes the replacement of output taxes by pollution taxes to raise the return on investment by reducing profits, thereby boosting growth. The overall effect on growth is positive if the aggregate burden of environmental policy on the production sector is small (i.e. $(\alpha \gamma-\epsilon \eta) \tilde{P}$ is small) and a large share of this burden can be shifted unto profits (i.e. $\tilde{w}$ is large and negative). By substituting (4.1) and (4.4) into (4.3), we derive the following condition for pollution taxes to boost the growth rate:

$$
\frac{\alpha \gamma-\epsilon \eta}{\alpha}<\left(1-\sigma_{y}\right) T_{F}^{*}
$$

The left-hand side (LHS) of (4.5) represents the net burden of less pollution on the production sector. In particular, if $\alpha \gamma-\epsilon \eta>0$, a decline in pollution hurts the production sector. The parameter $\alpha$ determines how effective pollution taxes are in cutting pollution. In particular, if $\alpha$ is large, pollution is an important factor of production reiative to abatement (i.e. $\alpha \gamma$ is large relative to $\gamma$ ). In that case, substantially lowering pollution is not attractive for firms, as the marginal product of pollution is highly sensitive to the flow of pollution. ${ }^{18}$

The RHS of (4.5) shows the benefits of pollution taxes in terms of shifting the tax burden away from the return on investment towards profits. If $\sigma_{y}=1$, the pollution tax and output tax imply the same relative burden on profits and the return on capital accumulation. Hence, an ecological tax reform does not imply a shift toward non-distortionary lump-sum taxation of profits. Accordingly, the tax-shifting effect exerts no positive effect on growth. If $\sigma_{y}<1$, however, compared to the output tax, the pollution tax is more effective in raising revenues without depressing the return to investment. The reason is that the tax on pollution is a more effective instrument to tax away profits (and the quasi-rents from pollution, in particular). Thus,

\footnotetext{
${ }^{18}$ In the extreme case that $a$ goes to infinity, pollution is not affected by a rise in the pollution tax. Hence, the costs of poilution taxes, represented by the LHS of (4.5), are zero.
} 
compared to an output tax, a pollution tax incorporates a more important lump-sum element. Accordingly, by using the revenues from the pollution tax to cat the distortionary tax on output (see (4.2)), the government shifts the tax burden away from the return on investment towards profits, thereby boosting growth.

On balance, an environmental tax reform stimulates growth if the positive effect of tax-shifting (which allows for a reduction in the wedge between the before- and after-tax return to capital) dominates the negative effect of input substitution on gross productivity associated with more public consumption in the form of more environmental amenities. Also Bovenberg and Van der Ploeg (1994b) find that, if an environmental tax reform shifts the burden of taxation from labor towards the rents from a fixed factor in production, it may boost employment. Similarly, Bovenberg and De Mooij (1994b) demonstrate that environmental taxes can yield a double dividend, by expanding employment and improving the environmer, if the burden of the public sector is shifted from workers towards transfer recipients.

\section{Welfare effects}

In section 3 we found that, in the Cobb-Douglas case, the optimal pollution tax is always below the Pigovian tax in the presence of environmental amenities. The reason is that lowering the pollution tax from the Pigovian level always boosts growth and, therefore, enhances welfare. If substitution is more difficult, the welfare effects of raising pollution taxes from its Pigovian level continues to be represented by (3.6). Hence, if pollution taxes succeed in raising growth, they improve welfare. Contrary to the Cobb-Douglas case, pollution taxes may indeed raise the growth rate if $\sigma_{y}<1$, even if environmental amenities cause the production elasticity to exceed the production externality (i.e. if $\alpha \gamma-\epsilon \eta=\epsilon \phi s_{c}>0$, see (4.5)). This is because raising pollution taxes may improve the efficiency of taxation by shifting the tax burden from the return on investment towards profits.

The smaller environmental amenities are, the more likely it will be that a rise in pollution taxes from the Pigovian level stimulates growth and thus improves welfare. This can be seen by substituting the Pigovian rule (3.5) and relation (E2) at the end of table 2 to eliminate $T_{p}^{*}$ and $\alpha \gamma$ from (4.5):

$$
s_{c} \epsilon \phi\left[1-\alpha\left(1-\sigma_{y}\right)\left(1-T_{y}\right)\right]<\alpha\left(1-\sigma_{y}\right)\left(1-T_{y}\right) \in \eta
$$

With $\sigma_{y}$ below unity, this inequality for growth to increase is met either if environmental amenities are small compared to production externalities or if large values for $\alpha$ ensure that pollution does not fall much. 


\section{Conclusions}

This paper has explored the consequences of an environmental tax reform for economic growth, pollution and welfare in a second-best framework in which the governmen has to employ distortionary taxes to finance public spending. Our analysis uncovered two channels through which an environmental $t a x$ reform may yield a double dividend, i.e. not only improve environmertal quality but also boost non-environmental welfare by stimulating economic growth. The first channel, discussed in section 3 , is a positive environmental externality in production associated with the role of the environment as a public production factor. Previous analyses of the double dividend issue ignored this channel by modelling the environment as a public consumption good rather than a public production factor. In that case, environmental policy always implied a net burden on the production sector of the economy, as the benefits accrued only to the household sector.

The second chanmei iirough which an environmental tax reform may boost growth is a shift in the tax burden away from the return on capital accumulation towards profits. In particular, section 4 showed that a pollution tax may improve the efficiency of the tax system as a revenueraising device by taxing away the quasi-rents from pollution. This second channel operates only if substitution between pollution and other inputs is difficult so that the base of the pollution tax is rather inelastic.

The role of the environmental tax as a lump-sum tax on rents suggests the importance of how environmental policy assigns property rights to the environnient. If the property rights would be assigned to pollutors, the quasi-rents from pollution would accrue to the owners of the firms rather than to the government. This would be the case if instruments were adopted itsat do not raise public revenues such as freely issued tradable permits. Accordingly, a double dividend cannot occur if the environmental externality in production is relatively small so that a decline in pollution imposes a net cost on the production sector. If the government owns the environment, in contrast, it can use the revenues from the sale of this public resource (i.e. the revenues from pollution taxes or the auctioning off of pollution permits) to cut distortionary taxes. In this case, a tighter environmental policy implies a capital loss for profit earners if substitution away from pollation is difficult. Hence, part of the burden of environmental policy on the production sector is borne by profits rather than the after-tax return to investment. If the tax-shifting away from the after-tax return towards profits is large enough, an ecological tax reform may enhance growth, even if environmental policy implies a net burden on the production sector. ${ }^{19}$

\footnotetext{
${ }^{19}$ Nielsen, Pedersen and Sørensen (1995) show that for this reason environmental taxes are a more efficient instrument to raise public revenues than freely issued tradable permits.
} 
In a second-best world with both environmental distortions and tax distortions, the optimal environmental tax typically differs from the Pigovian level. We find that the role of the environment as a public production factor does not overturn the result derived by Bovenberg and de Mooij (1994a) that the optimal pollution tax is lower than the Pigovian tax. As long as the environment produces some environmental amenities as a public consumption good, the Pigovian tax exceeds the optimal pollution tax, which internalizes the adverse pollution externalities on consumption. Intuitively, at the optimal tax level, the pollution tax reduces growth, thereby worsening distortions due to the absence of lump-sum taxation. However, we also demonstrated that the optimal environmental tax may exceed its Pigovian level if the government has no access to more direct ways to tax rents. Intuitively, in the absence of an explicit lump-sum tax on profits, the pollution tax acts an implicit way to tax rents. For the optimal environmental tax to exceed the Pigovian level, the pollution tax should be rather ineffective in cutting pollution. In that case, the shifting of the burden of public spending and environmental amenities to the owners of the firm offsets the costs of additional environmental amenities, thereby alleviating the net burden on investors so that the after-tax return on investment, and with it growhli, rise.

\section{Appendix A: Linearizing the factor demand equations}

We log-linearize the model around an initial equilibrium. A tilde () above a variable denotes a relative change, unless indicated otherwise.

\section{Specification of $F$}

$F=f(M, N)$ is homogenous of degree 1 in $M$ and $N$. Hence, $F / M=f(1, N /$ $M) \rightarrow \phi=\phi(z)$ where $\phi=F / M$ and $z=N / M$. The first-order derivatives of $F$ are:

$$
\begin{aligned}
& \frac{\partial F}{\partial N}=\phi^{\prime} \\
& \frac{\partial F}{\partial M}=\phi-z \phi^{\prime}
\end{aligned}
$$

The substitution elasticity between $M$ and $N$ is defined as:

$$
\frac{1}{\sigma_{y}}=-\frac{\partial\left(\frac{\partial F / \partial N}{\partial F / \partial M}\right)}{\partial \frac{N}{M}} \frac{\frac{N}{M}}{\frac{\partial F / \partial N}{\partial F / \partial M}}=\frac{-z \phi^{\prime \prime}}{\phi^{\prime}} \frac{\phi}{\phi-z \phi^{\prime}}
$$




\section{Specification of $M$}

$M=m(K, S)$ is homogenous of degree 1 in $K$ and $S$. Hence, $M / K=m(1$, $S / K) \rightarrow \mu=\mu(s)$ where $\mu=M / K$ and $s=S / K$. The first order derivatives of $M$ are:

$$
\begin{aligned}
& \frac{\partial M}{\partial S}=\mu^{\prime} \\
& \frac{\partial M}{\partial K}=\mu-s \mu^{\prime}
\end{aligned}
$$

The substitution elasticity between $K$ and $S$ is defined as:

$$
\frac{1}{\sigma_{m}}=-\frac{\partial\left(\frac{\partial M / \partial S}{\partial M / \partial K}\right)}{\partial \frac{S}{K}} \frac{\frac{S}{K}}{\frac{\partial M / \partial S}{\partial M / \partial K}}=\frac{-s \mu^{\prime \prime}}{\mu^{\prime}} \frac{\mu}{\mu-s \mu^{\prime}}
$$

From the definitions of the production elasticities, the Cobb-Douglas specification of $N$ and (A4) and (A5), we derive:

$$
\begin{gathered}
\gamma=\frac{\partial Y}{\partial A} \frac{A}{Y}=\left[\frac{\partial F}{\partial N} \frac{N}{F}\right]\left[\frac{\partial N}{\partial A} \frac{A}{N}\right]=\frac{\partial F}{\partial N} \frac{N}{F} * 1 \\
\beta+\delta=\frac{\partial Y}{\partial K} \frac{K}{Y}+\frac{\partial Y}{\partial S} \frac{S}{Y}=\frac{\partial F}{\partial M} \frac{M}{F}\left[\frac{\partial M}{\partial K} \frac{K}{M}+\frac{\partial M}{\partial S} \frac{S}{M}\right] \\
=\frac{\partial F}{\partial M} \frac{M}{F} * 1
\end{gathered}
$$

Homogeneity of $F$ and $M$ and using (A7) and (A8) implies:

$$
\begin{aligned}
& \tilde{F}=\gamma \tilde{N}+(\delta+\beta) \tilde{M}=\tilde{N}+(\delta+\beta)[\tilde{M}-\tilde{N}] \\
& \tilde{M}=\frac{\beta}{\beta+\delta} \tilde{K}+\frac{\delta}{\beta+\delta} \tilde{S}
\end{aligned}
$$

where we have used $(2.1)$.

\section{Specification of $N$ and $Y$} N:

The Cobb Douglas sperification for $N$ implies for the rclative change in

$$
\tilde{N}=\tilde{A}+\alpha \tilde{P}
$$

Moreover, the externality of pollution specified in (1.1) implies for the relative change in $Y$ :

$$
\tilde{Y}=\tilde{F}+\eta \tilde{E}
$$




\section{Linearizing marginal factor productivity}

Armed with this set of definitions and relations, we are able to loglinearize the factor demand equations (I.6), (I.7) and (1.8) for abatement, pollution and capital, respectively. The relative change in the marginal product of abatement is derived by using (A1), (A3) and the Cobb Douglas specification of $N$ in the production function (I.1):

$$
\begin{aligned}
\frac{\Delta \partial Y / \partial A}{\partial Y / \partial A}= & \frac{\Delta \partial F / \partial N}{\partial F / \partial N}+\eta \tilde{E}+\frac{\Delta \partial N / \partial A}{\partial N / \partial A}=-\frac{1}{\sigma_{y}} \\
& \times(\beta+\delta)[\tilde{N}-\tilde{M}]+\alpha \tilde{P}+\eta \tilde{E}
\end{aligned}
$$

The linearized marginal product of pollution is found by using the same relations as for abatement:

$$
\begin{aligned}
\frac{\Delta[\partial / F / \partial P] E^{\eta}}{\partial Y / \partial P}= & \frac{\Delta \partial F / \partial N}{\partial F / \partial N}+\eta \tilde{E}+\frac{\Delta \partial N / \partial P}{\partial N / \partial P}=-\frac{1}{\sigma_{y}} \\
& \times(\beta+\delta)[\tilde{N}-\tilde{M}]+\tilde{A}-(1-\alpha) \tilde{P}+\eta \tilde{E}
\end{aligned}
$$

To derive an expression for the relative change in the marginal product of capital, we use (A2), (A3), (A.5), (A6) and the specification of the production function (1.1):

$$
\begin{aligned}
\frac{\Delta \partial Y / \partial K}{\partial Y / \partial K}= & \frac{\Delta \partial F / \partial M}{\partial F / \partial M}+\eta \tilde{E}+\frac{\Delta \partial M / \partial K}{\partial M / \partial K}=\frac{1}{\sigma_{y}} \\
& \times \gamma[\tilde{N}-\tilde{M}]+\frac{1}{\sigma_{m}} \frac{\delta}{\beta+\delta}[\tilde{S}-\tilde{K}]+\eta \tilde{E}
\end{aligned}
$$

Linearizing factor demand equations

Using (A13), we linearize the demand for abatement (I.6) as:

$$
\frac{1}{\sigma_{y}}(\beta+\delta)[\tilde{N}-\tilde{M}]-\alpha \tilde{P}-\eta \tilde{E}=\tilde{T}_{u}-\tilde{T}_{y}
$$

From (A14), we arrive at the following linearized demand for pollution (I.7):

$$
-\frac{1}{\sigma_{y}}(\beta+\delta)[\tilde{N}-\tilde{M}]+\tilde{A}-(1-\alpha) \tilde{P}+\eta \tilde{E}=\tilde{T}_{p}+\tilde{T}_{y}
$$

By adding (A16) and (A17), we find the following relation between abatement and pollution:

$$
\tilde{A}=\tilde{P}+\tilde{T}_{p}+\tilde{T}_{a}
$$


Combining (A10) and (A18), we derive for abatement and pollution:

$$
\begin{aligned}
& \tilde{A}=\frac{1}{1+\alpha} \tilde{N}+\frac{\alpha}{1+\alpha}\left[\tilde{T}_{p}+\tilde{T}_{a}\right] \\
& \tilde{P}=\frac{1}{1+\alpha} \tilde{N}-\frac{1}{1+\alpha}\left[\tilde{T}_{p}+\tilde{T}_{a}\right]
\end{aligned}
$$

Finally, (A15) and (1.8) yield for the desired demand for capital:

$$
\frac{1}{\sigma_{y}} \gamma[\tilde{N}-\tilde{M}]+\frac{1}{\sigma_{m}} \frac{\delta}{\beta+\delta}[\tilde{S}-\tilde{K}]+\eta \tilde{E}=\tilde{r}+\tilde{T}_{y}
$$

Now we are able to derive the factor-demand equations as presented in table II. First, the rate of return to capital (II.4) is found by substituting (A9), (A10) and (A12) into (A21) to eliminate $\tilde{N}, \tilde{M}$ and $\tilde{F}$, respectively. Second, relation (II.2) for pollution is found by substituting (A10) and (A11) into (A16) to eliminate $N$ and $\tilde{M}$, and then using (1I.4) to eliminate $\tilde{Y}$. Finally, (II.3) is equivalent with (A18).

\section{Appendix B: Welfare Effects}

This appendix derives the marginal excess burden as a measure for changes in social welfare. It represents the welfare changes due to various policy measures in terms of consumption.

Utility is defined in (1.9). On the sustainable balanced-growth path private consumption grows at a constant rate, $\pi$, while pollution remains constant. Hence, we can rewrite utility as:

$$
U=\frac{\left[C_{0} E^{\psi}\right]^{1-\frac{1}{\sigma}}}{1-\frac{1}{\sigma}} \int_{0}^{\infty} \mathrm{e}^{\left[\pi\left(1-\frac{1}{\sigma}\right)-\theta\right]} \mathrm{d} t
$$

where $C_{0}$ is the initial consumption level. To solve the integral at the RHS of (B1), we require that $\pi(1-1 / \sigma)-\theta<0$ so that that utility is bounded. Using (I.11) from table I, we rewrite this condition as follows:

$$
\theta-\pi\left(1-\frac{1}{\sigma}\right)=r-\pi>0
$$

Solving the integral in (B1) yields the following expression for utility:

$$
U=\frac{\left[C_{0} E^{\phi}\right]^{1-\frac{1}{\sigma}}}{\left(1-\frac{1}{\sigma}\right)\left(\theta-\pi\left(1-\frac{1}{\sigma}\right)\right)}
$$


For utility to remain constant after a policy shock, we need:

$$
0=\mathrm{d} U=\frac{\partial U}{\partial C} \mathrm{~d} C+\frac{\partial U}{\partial E} \mathrm{~d} E+\frac{\partial U}{\partial \pi} \mathrm{d} \pi
$$

The derivatives at the right-hand side of (B4) can be derived by differentiating (B3) with respect to the respective arguments. This yields:

$$
\begin{aligned}
& \frac{\partial U}{\partial C} \mathrm{~d} C=\frac{\left[C_{0} E^{\phi}\right]^{1-\frac{1}{\sigma}}}{r-\pi} \tilde{C} \\
& \frac{\partial U}{\partial E} \mathrm{~d} E=\frac{\left[C_{0} E^{\phi}\right]^{1-\frac{1}{\sigma}}}{r-\pi} \phi \tilde{E} \\
& \frac{\partial U}{\partial \pi} \mathrm{d} \pi=\frac{\left[C_{0} E^{\phi}\right]^{1-\frac{1}{\sigma}}}{r-\pi} \frac{\pi}{r-\pi} \tilde{\pi}
\end{aligned}
$$

Substituting (B5), (B6) and (B7) into (B4), we arrive at the following expression for the change in welfare:

$$
\tilde{\lambda}+\tilde{C}+\phi \tilde{E}+\frac{\pi}{r-\pi} \tilde{\pi}=0
$$

where $\tilde{\lambda}=(\mathrm{d} \lambda / C)$ is the additional consumption that needs to be provided to the household in order to keep utility, after the policy shock, at its initial level. It is denoted as the marginal excess burden.

To arrive at an alternative formulation for the marginal excess burden in (B8), we substitute (II.1) into (II.12) to eliminate consumption. Thus, we find:

$$
\tilde{\Lambda}=-\phi \tilde{E}-\frac{\pi}{r-\pi} \tilde{\pi}-\frac{\delta-s_{s}}{s_{c}} \tilde{s}-\frac{\gamma-s_{a}}{s_{\mathrm{c}}} \tilde{a}-\frac{\alpha \gamma-\epsilon \eta}{s_{c}} \tilde{P}+\frac{s_{i}}{s_{\mathrm{c}}} \tilde{i}
$$

To rewrite (B9), we first substitute (II.11) into (B9) to eliminate $\tilde{E}$. Then we use the production elasticity (E1) at the end of table II to rewrite the coefficient for abatement. By using (II.7), we can eliminate $\tilde{i}$. Finally, by using the relations between the shares $(\mathbf{S} 2)$ and (S6), the production elasticity $(\mathrm{E} 3)$ and relation $(2.1)$, we derive the following relationship:

$$
(r-\pi) s_{k}=s_{c}-\left(\delta-s_{s}\right)-\left(\gamma-s_{u}\right)-t_{y} \beta
$$

Using (B10) and (S2), we can rewrite the coefficient for growth in the marginal excess burden (B9) as in (2.2). 


\section{Appendix C: Solution of the model}

This appendix solves the model of table II for the case the government uses $T_{v}$ to balance its budget (ex post). We assume that $\delta=s_{s}, T_{a}=T_{v}$ and $\tilde{T}_{a}=\tilde{S}^{v}=0$. This appendix makes extensive use of the relations between shares and the definitions of the production elasticities at the end of table II.

By subsituting (II.3) and (II.11) into (II.1), we can write output as:

$$
\bar{y}=[\gamma+\alpha \gamma-\epsilon \eta] \tilde{P}+\gamma \tilde{t}_{p}
$$

Then we substitute (C1) into (II.4) to eliminate $\tilde{y}$ and use (II.11) to eliminate $\tilde{E}$. This yields:

$$
\sigma_{v} \tilde{r}=\left[\gamma+\alpha \gamma-\sigma_{y} \epsilon \eta\right] \tilde{P}+\gamma \tilde{t}_{p}-\sigma_{y} \tilde{T}_{y}
$$

Substitution of (C2) into (II.2) to eliminate $\tilde{r}$, we arrive at the following relation:

$$
\left[(1-\gamma)(1+\alpha)+\sigma_{y}(\epsilon \eta-\alpha)\right] \tilde{P}+\sigma_{y} \tilde{T}_{y}=-(1-\gamma) \tilde{t}_{p}
$$

By substituting $\tilde{y}$ and $\tilde{s}$ from (C1) and (II.3) into the government budget constraint (II.10), we find another expression for $\tilde{P}$ and $\tilde{T}_{y}$ in terms of the exogenous variables:

$$
\left[\alpha \gamma-T_{y} \in \eta\right] \tilde{P}+\left(1-T_{y}\right) \tilde{T}_{y}=-T_{p}^{*} \tilde{t}_{p}
$$

Relations (C3) and (C4) form two linear equations in two endogenous variables. Rewriting them in matrix notation yields:

$$
\left(\begin{array}{cc}
1-T_{y} & \alpha \gamma-T_{y} \epsilon \eta \\
\sigma_{y} & (1-\gamma)(1+\alpha)+\sigma_{y}(\epsilon \eta-\alpha)
\end{array}\right)\left(\begin{array}{c}
\tilde{T}_{y} \\
\tilde{P}
\end{array}\right)=\left(\begin{array}{c}
-T_{p}^{*} \\
-(1-\gamma)
\end{array}\right) \tilde{t}_{p}
$$

Solving this linear system by inverting the matrix at the left-hand side of (C5), we find:

$$
\Delta^{*}\left(\begin{array}{c}
\tilde{T}_{y} \\
\tilde{P}
\end{array}\right)=\left(\begin{array}{cc}
(1-\gamma)(1+\alpha)+\sigma_{y}(\epsilon \eta-\alpha) & T_{y} \epsilon \eta-\alpha \gamma \\
-\sigma_{y} & 1-T_{y}
\end{array}\right)\left(\begin{array}{c}
-T_{p}^{*} \\
-(1-\gamma)
\end{array}\right) \tilde{t}_{p}
$$

where:

$$
\begin{aligned}
\Delta^{*} & =\left(1-T_{y}\right)(1-\gamma)(1+\alpha)-\sigma_{y}\left[\alpha \gamma-\epsilon \eta+\left(1-T_{y}\right) \alpha\right] \\
& =\sigma_{y}\left[r s_{k}+s_{w^{\prime}}-(\alpha \gamma-\epsilon \eta)\right]+\left(1-\sigma_{y}\right)\left(1-T_{v}\right)(1-\gamma)(1+\alpha)
\end{aligned}
$$

The determinant in (C7) should be positive for the equilibrium to be stable. (C6) yields the reduced-form equations for the output tax and poliution: 


$$
\begin{aligned}
\Delta^{*} \tilde{T}_{y} & =s_{s}(\alpha \gamma-\epsilon \eta) \tilde{t}_{p}-\left(1-\sigma_{y}\right) T_{p}^{*}(\alpha-\epsilon \eta) \tilde{t}_{p} \\
\Delta^{*} \tilde{\boldsymbol{P}} & =-\left[r s_{k}+s_{w}\right] \tilde{t}_{p}-\left(1-\sigma_{y}\right) T_{p}^{*} \tilde{t}_{p} \\
& =-\Delta^{*} \tilde{t}_{p}+\left(1-\sigma_{y}\right)\left(1-T_{y}\right)(1-\gamma) \alpha \tilde{t}_{p}-\sigma_{y}(\alpha \gamma-\epsilon \eta) \tilde{t}_{n}
\end{aligned}
$$

Substituting (C3) into (II.2) to eliminate $\tilde{\boldsymbol{P}}$, we find for the interest rate:

$$
\left[(1-\gamma)(1+\alpha)+\sigma_{y}(\epsilon \eta-\alpha)\right] \tilde{r}=-(\alpha \gamma-\epsilon \eta) \tilde{t}_{p}-\left[1+\alpha\left(1-\sigma_{y}\right)\right] \tilde{T}_{y}
$$

In order to find the reduced form for the interest rate we substitute (C8) into (C10). After some tedious algebra, we find:

$$
\Delta^{*} \tilde{r}=-(\alpha \gamma-\epsilon \eta) \tilde{t}_{p}+\left(1-\sigma_{y}\right)\left(1-T_{y}\right) \alpha \gamma \alpha \tilde{t}_{p}
$$

The reduced form for the growth rate is closely related to (C11) (see (II.7) and (II.8)). The reduced form for the marginal excess burden can be derived by substituting the reduced forms for pollution and growth into (2.2).

In order to gain more insight into the effects of pollution taxes on the interest rate, we derive another expression for $\tilde{r}$. By substituting (II.5) into (II.6) to eliminate $\tilde{d}$, we find for profits:

$$
s_{w} \tilde{w}=-\left(1-T_{y}\right)\left[\tilde{T}_{y}+\alpha \gamma \tilde{t}_{p}+\epsilon_{\eta} \tilde{P}+\beta \tilde{r}\right]
$$

Substituting (C4) into (C12) to eliminate $\tilde{T}_{y}$ and rearranging terms, we find the foliowing expression for the interest rate:

$$
\left(1-T_{y}\right) \beta \tilde{r}=(\alpha \gamma-\epsilon \eta) \tilde{P}-s_{w} \tilde{w}
$$

The reduced form for profits is derived by substituting (C9) and (Cl1) into (C13).

$$
\Delta^{*} \ddot{w}=-(\alpha \gamma-\epsilon \eta) \tilde{t}_{p}-\frac{\alpha \gamma}{\hat{o}-\alpha \gamma}\left(1-\sigma_{y}\right)\left[\alpha \gamma-\epsilon \eta+\alpha r s_{k}\right] \tilde{t}_{p}
$$

\section{References}

Alfsen, K., A. Brendemoen and $S$, Giomsrod, 1992, Benefits of elimate policies: some tentative calculations, Discussion paper no.69, Statistics Norway.

Ballard. C.L. and S.G. Medema. 1993. The marginal efficiency effects of taxes and subsidies in the presence of externalities, Journal of Public Economics 52, 199-216.

Barro, R.J., 199), Government spending in a simple model of endogenous growth. Journal of Political Economy 98, 103-125.

Barro, R.J., and X. Sali-i-Martin, 1992, Public finance in models of economic growth, Review of Economic Studies 59, 645-661.

Berndt, E.R. and D.O. Wood, 1979, Engineering and econometric interpretations of energycapital complementarity. American Economic Review 69, 342-354. 
Brendemoen, A. and H. Vennemo, 1994, $A$ climate treaty and the Norwiglan Economy: $A$ CGE assessment, The Energy Journal 15, 77-93.

Bovenberg. A.L. and R.A. de Mooij, 1994a, Environmental levies and distortionary taxation, American Economic Review 94, 1085-89.

Bovenberg, A.L. and R.A. de Mooij, 1994b, Environmental policy in a small open economy with distortionary labor taxes: a general equilibrium analysis, in: E.C. van lerland, ed., Internationai Environmental Economics (Elsevier, Amsterdam).

Bovenberg, A.L. and F. van der Ploeg, 1994a, Environmental policy, public finance and the labour market in a second-best world, Journal of Public Econornics 55, 349-390.

Bovenberg. A.L. and F. van der Ploeg. 1994b. Consequences of environmental tax reform for involuntary unemployment and welfare, CentER Discussion Paper 9408. Tilburg University.

Bovenberg, A.L., and S. Smuilers, 1994, Transitional Impacts of Environmental Policy in an Endogenous Growth Model, CentER Discussion Paper, No. 9450. Tilburg University.

Bovenberg, A.L. and S. Smulders, 1995, Environmental quality and pollution-saving technological change in a two sector endogenous growth model, Journal of Public Economics 57. 369-391.

Butter, F.A.G. den, and M.W. Hofkes, 1993, Sustainable development with extractive and non-extractive use of the environment in production, Discussion Paper 93-194. Tinbergen Institute.

Ewijk, C. van, and S. van Wijnbergen, 1995, Can abatement overcome the conflict between the environment and economic growth?, De Economist 143, 197-216.

Goulder, L.H., 1995a, Effects of carbon taxes in an economy with prior tax distortions: An intertemporal general equilibrium analysis, Journal of Environmental Economics and Management, in press.

Goulder, L.H., 1995b, Environmental taxation and the double dividend: A reader's guide, International Tax and Public Finance 2, 155-182.

Gradus, R., and S. Smulders, 1993, The trade-off between environme, tal care and long-term growth - pollution in three prototype growth nodels, Journal of Fconomics 58, 25-51.

Griffin, J.M., 1981. Engineering and econometric interpretations of energy-capital complementarity: Comment, American Economic Review 71, 1100-1105.

Hesse, D.M. and H. Tarkka, 1986, The demand for capital, labor and energy in European Manufacturing industry hefore and after the oil price shocks, Scandinavian Journal of Economics 88, 529-546.

Ligthart, J.E. and F. van der Ploeg, 1994, Environmental quality, public finance and sustainable growth, in: C. Carraro and J Filer, eds., Control and game theoretic models of the environment (Birkhauser).

Nielsen, S.B., L.H. Pedersen, and P.B. Sørensen, 1995, Environmental policy, pollution, unemployment, and endogenous growth, International Tax and Public Finance 2, 183-204.

Oates, W.E., 1995, Green taxes: Can we protect the environment and improve the tax system at the same time?, Southern Economic Journal 61, 915-922.

Parry, 1.H., 1995, Pollution taxes and revenue recycling, Journal of Environmental Economics and Management, in press.

Pezzey, J., 1992, Sustainability: an interdisciplinary guide, Environmental Values 1, 321-362.

Pindyck, R.S., 1979, Interfuel substitution and the industrial demand for energy: an international comparison, Review of Economic Studiss LXI, 169-179.

Ploeg, F. van der and C. Withagen, 1991. Pollution control and the Ramsey problem, Environmental and Resource Economics 1, 215-36.

Proost, S. and D. van Regemorter, 1995, The double dividend and the role of inequality aversion and macrocconomic regimes, International Tax and Public Finance 2, 205-218.

Rebelo, S., 1991, Long-run policy analysis and long-run growth, Journal of Political Economy 99. 500-521. 
Schöb, R., 1994, Evaluating tax reforms in the presence of externalities. paper presented at the 50th IIPF congress, Harvard, Cambridge MA.

Siebert, H., J. Eichenberger, R. Gronych and R. Pethig. 1980, Trade and environment:A theoretical inquiry, (Elsevier).

Smulders, S., and R. Gradus, 1995, Pollution abatement and long-term growth, mineo, Tilburg University.

Tahvonen, O. and J. Kuuluvainen, 1993, Economic growsh, pollution and renewable resources. Journal of Environmental Economics and Management 24, 101-118.

Ulph, D., 1992, $A$ note on the 'Double Dividend' of pollution taxes, University of Bristol, Discussion Paper 92/317. 